\title{
Biometals 2010 (Tucson, Arizona, USA)
}

\author{
Megan M. McEvoy $\cdot$ Christopher Rensing
}

Received: 20 February 2011/Accepted: 22 February 2011/Published online: 9 March 2011

(C) Springer Science+Business Media, LLC. 2011

This issue of Biometals features some of the exciting science presented at the 7th International Symposium on Biometals (Biometals 2010) in Tucson, Arizona, USA. The Symposium was held at the Westin La Paloma Resort at the foothills of the Santa Catalina Mountains from July 25-30, 2010, with the dramatic desert landscape serving as an attractive backdrop to the scientific sessions. Approximately 150 participants representing 20 different countries attended the symposium. The scientific program included sessions dedicated to siderophores and iron transport, arsenic toxicity and transformation, interplay of metals, metals and gene regulation, metals in disease, metal transport, and metals in microorganisms. The articles in this issue represent both oral and poster presentations from the different sessions and underscore the breadth of topics discussed at the meeting. We are pleased to showcase some of the stimulating findings of the researchers in the biometals field in this special issue. Also in this issue, one of the founding fathers of "Biometals", Simon Silver, contributed a personal account of his journey through metal related research, adding to the human aspect of scientific discovery. This meeting witnessed the birth of the International

M. M. McEvoy · C. Rensing ( $₫)$

University of Arizona, Tucson, USA

e-mail: rensingc@Ag.arizona.edu

M. M. McEvoy

e-mail: mcevoy@email.arizona.edu
Biometals Society which is briefly introduced in this issue.

One highlight of the symposium was the ceremony for the presentation of the Igor Stojiljkovic Memorial Awards. The Lecturer Award was presented to Prof. Klaus Hantke of the University of Tübingen, in recognition of his outstanding contributions in the biometals field towards understanding iron transport (Fig. 1). Prof. Hantke delivered the closing lecture. Two other awards in honor of Igor Stojiljkovic were given at the postdoctoral and graduate student level to acknowledge significant contributions in biometals research by early career investigators. The postdoctoral award recipient was Deenah Osman, a researcher in the laboratory of Prof. Jennifer Cavet at the University of Manchester (Fig. 2). Federico Rosconi, from the Instituto de Investigaciones Biológicas Clemente Estable, Montevideo, from the laboratory of Prof. Elena Fabiano, was the recipient of the graduate student award (Fig. 3). These individuals were selected for the awards by the organizers and other members of the Biometals committee. The competition for these awards was fierce, due to the high quality of the presentations by all the students and postdoctoral researchers. All participants are to be commended for their efforts. We would like to express our appreciation to Prof. Jorge Crosa for his efforts in organizing the awards and presentation of the plaques, and we are thankful to the Emory University Memorial Fund for their support. 


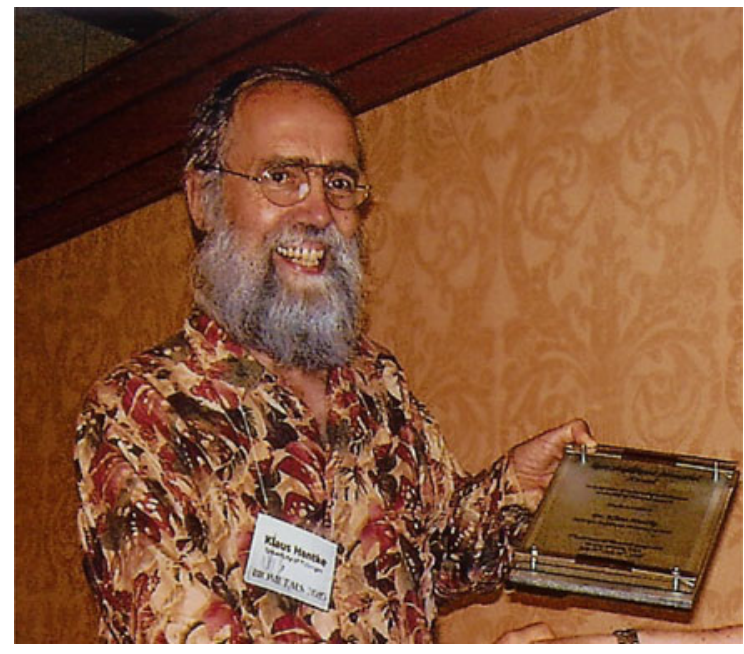

Fig. 1 Professor Klaus Hantke, recipient of the Igor Stojiljkovic Memorial Lecturer Award

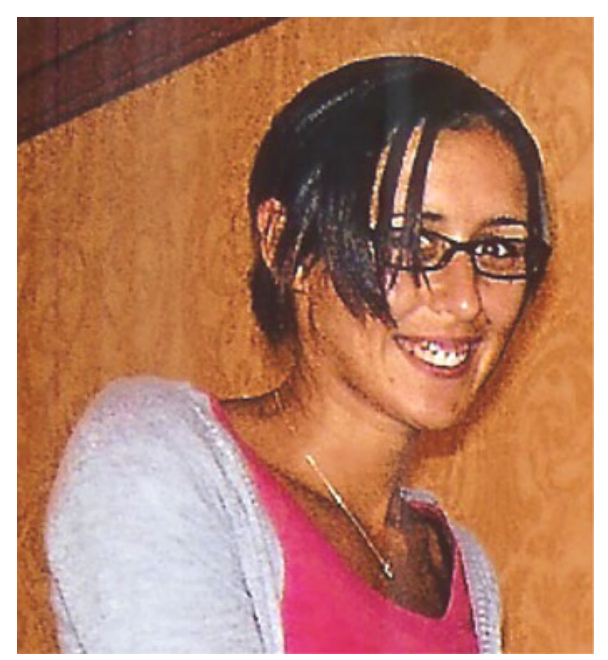

Fig. 2 Dr. Deenah Osman, recipient of the Igor Stojiljkovic Postdoctoral Award

We gratefully acknowledge contributions from many sponsors, which helped to make the meeting a

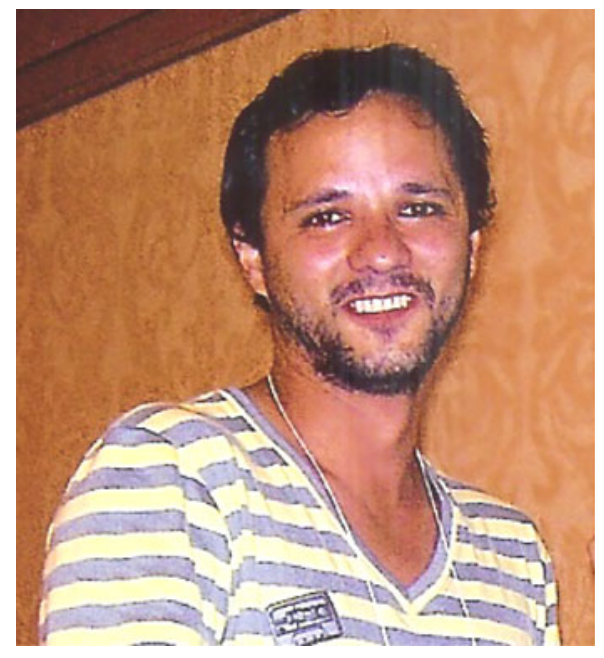

Fig. 3 Federico Rosconi, recipient of the Igor Stojiljkovic Graduate Student Award

grand success. These sponsors include: National Institute of Environmental Health Sciences, Society of Biological Inorganic Chemistry, Freeport-McMoran Copper \& Gold, Metallomics, Superfund Research Program, Water Sustainability Project, University of Arizona Departments of Chemistry \& Biochemistry and Nutritional Sciences, Fisher Scientific, and Springer.

In conclusion, the articles in this special issue are a sampling of some of the tremendous science that was presented and discussed at the Biometals 2010 symposium. We thank all the participants of the meeting for an energizing and enjoyable conference, and additionally thank the contributors to this special issue. The 8th International Biometals Symposium will be held in July 2012 in Brussels, Belgium, hosted by Professors Pierre Cornelis, Nathalie Verbruggen, Jaco Van Gronsveld, Max Mergeay and Joris Messens. We look forward to more exciting science from the biometals community at this symposium. 